\title{
How Group Singers Influence Cultural Exportation: South Korean Entertainment Industry vs. Chinese Entertainment Industry
}

\author{
Kexin $\mathrm{Yu}^{1, *}$ \\ ${ }^{1}$ Bachelor of Arts, Miami University, 45056, Oxford, Ohio, United States \\ *Corresponding author.Email: yuk6@miamioh.edu
}

\begin{abstract}
This paper studies how group singers in the entertainment industry can help a country to promote cultural exportation by using the data comparison method. This paper compares group singers' member corporation, business model, popularity, and ranking, as well as the voting system of two shows from China and South Korea. Based on the comparison of these data, it concludes that a group singer with members from different countries has a more positive influence on cultural exportation. A normative voting system can avoid events that violate social morality and negatively impact cultural output. The more exposure group singers have, the easier it is to promote cultural output. The more popular and internationally ranked group singers are, the more opportunities they have to collaborate with famous local artists and develop cultural exportation. This paper provides suggestions and new ideas for the Chinese entertainment industry to promote cultural exportation.
\end{abstract}

Keywords: Cultural Exportation, Cultural Output, Group Singers, Entertainment industry.

\section{INTRODUCTION}

In recent years, "Korean wave" has become a word that frequently appears among the young generation and is widely spread around the world [1]. The widespread activities such as roadshow, talent show, and offline random dance related to the Korean wave in the world have proved that South Korea's cultural exportation is successful. Why South Korea's cultural exportation has been so successful? Why does China not make such progress in cultural exportation? Cultural exportation is a big topic that always accompanies social development and national development. Cultural exportation can help a country bring strong economic benefits [2], enhance cultural soft power [3], expand a country's influence in the world [4], and attract more people to learn the local culture. The success of cultural output can improve the status of a country in the world, which is also the most important reason for cultural exportation. "The process of enhancing cultural output ability is also the process of enhancing cultural soft power, which is of positive significance to the promotion of China's international competitiveness" [5]. China's cultural output mainly relies on the rapid development of its economic strength, but it lacks cultural exportation on the soft power of pop culture. In view of cultural exportation is a hot topic, many scholars have done studies related to cultural output. They analyzed the enlightenment of soft power of Korean pop culture to China [6], the predicament of China's cultural exportation [7], the success of South Korea's cultural exportation through variety shows [8], TV drama and movies [9], and the Korean popular (Kpop) music [1]. These studies have analyzed the success of South Korea in cultural exportation from many aspects and studied the bottleneck of China in cultural exportation. However, they lack a comparative perspective to study the differences in cultural exportation between China and South Korea.

This paper analyses the influence of these factors on cultural output by comparing the member composition, business model, international popularity, and ranking of Chinese and South Korean group singers, and the voting system of two talent shows. Firstly, it analyzes the different effects and influences of cultural output caused by the different distribution of members in Chinese and South Korean group singers. Secondly, comparing the different voting systems analyzes the advantages and disadvantages of related events caused by the standardization of voting systems on cultural output. Thirdly, different results of cultural output are analyzed 
by comparing the different business models of Chinese and South Korean group singers who came from talent shows. Finally, the international popularity of the Chinese and South Korean group singers is compared to analyse their influence on cultural exportation. This paper also criticizes some events that violate social morality and fairness in the entertainment industry, such as the negative impact of data brushing and "milk pouring incident" on the corresponding cultural exportation. This paper provides suggestions for the Chinese entertainment industry on the development and business model of group singers to contribute to the export of Chinese culture.

\section{METHODOLOGY}

\subsection{Data Collection}

The data of this paper were mainly collected from Baidu Baike (baike.baidu.com). The information of group singer's albums sold, the number of music albums released, and the number of music songs was collected from QQ Music. The comparative data of variety shows, ranking, popularity, and voting system were collected from Youtube, Bilibili (bilibili.com), Twitter, Weibo, and Billboard (billboard.com). Some news reports about entertainment events, variety shows and voting systems were collected from Zhihu (zhihu.com) and Renminwang (media.people.com.cn). All the data are publicly available for people to finds and do not have any ethical implications.

\subsection{Data Analysis}

Data analysis is divided into four stages, which involves group singers' comparison and the voting system comparison of two variety shows. The first stage compares the distribution of group members between China and South Korea, mainly to analyze the advantages and disadvantages of memberships' nationality composition for cultural export. The second stage compares voting systems' professionalism and rationality in China and South Korea to analyze the influence of "fan voting" on cultural output. The data gave some examples of a "fan voting" system to criticize the negative impact of cultural export. The third stage compares group singers from China and South Korea who are debuted from the talent show. Data analysis is made from the number of albums, songs, variety shows, concerts, and the countries and cities where the concert was held to reflect China and South Korea's importance to the management of group singers and the corresponding cultural output results. The last stage compares the popularity of group singers, including followers and subscribers on social media platforms. Comparing the song ranking, artist ranking, and the influence of the group singers from China and South Korea analyzed the reasons for the success or failure of the group singers in cultural export.

\section{RESULT AND DISCUSSION}

\subsection{Member Corporation Comparison}

NCT127 is a popular group singer from South Korea who has 5.9 million fans on Twitter. TNT is one of the most popular among the few group singers in China, and they have 7 million fans on Weibo. According to Table 1, the member of South Korean group singer NCT127 comes from many countries, among which six are South Korean, one is Chinese, two are American, and one is Japanese. The members of the Chinese group singer TNT are all Chinese nationals. NCT127, a multi-national group of singers, can gain a fan base in different countries. According to Table 2, NCT127 had a certain search volume in Indonesia, Thailand, the United States, South Korea, and Japan from May 2020 to May 2021, and the number of searches was quite high. However, TNT does not have any data.

The data shows that NCT127 has a fan base in many countries worldwide, not just in South Korea. If a group singer is made up of different countries, it is easy to export culture in the later stages of the group's development. First, they have different cultural backgrounds, there are known for their respective national culture. They can contact the fans and the media platform in different countries to reduce language communication barriers. This kind of culture and development later became the "language" they output the most advantageous factors for culture.

Table 1. The member corporation and nationality of NCT 127 and TNT.

\begin{tabular}{|c|c|c|c|c|}
\hline Group Name & Chinese & South Korean & American & Japanese \\
\hline NCT 127 & 1 & 6 & 2 & 1 \\
\hline TNT & 7 & 0 & 0 & 0 \\
\hline
\end{tabular}


Table 2. The number of searches of NCT127 in five countries

\begin{tabular}{lccccc}
\hline Group Name & Indonesia & Thailand & United States & South Korea & Japan \\
\hline NCT127 & $107 \mathrm{M}$ & $82.4 \mathrm{M}$ & $58.8 \mathrm{M}$ & $57.9 \mathrm{M}$ & $31.3 \mathrm{M}$ \\
TNT & - & - & - & - & - \\
\hline
\end{tabular}

\subsection{Voting System Comparison}

This section compares the voting system between the shows from South Korea and the shows from China. In South Korea, people can vote for their favorite group singers in four ways. Taking the Music Bank Voting System as an example, Figure 1 shows that the first one is the audio source, accounting for $65 \%$. The votes are counted by the number of times people listen to the music. The second one is the number of tracks played, which accounts for $20 \%$. Group singers earn points depends on how many times they perform on stage. Third one is popularity, which accounts for $10 \%$. People can vote by sending text messages to the corresponding platform system during the broadcast period of the program to choose their favorite stage performances. Last one is the album sales which account for 5\%. The group singers with higher album sales will get higher scores. The voting process is fair, and the voting data is public.

\section{KBS-Music Bank Voting System}

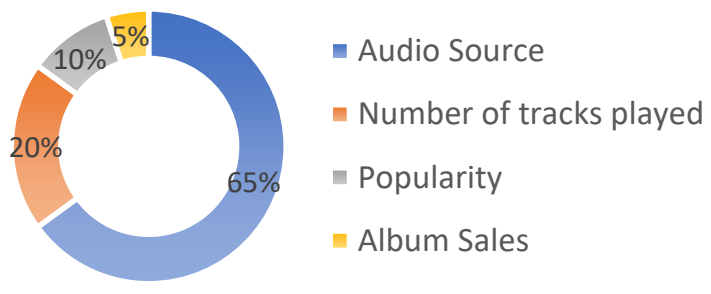

Figure 1. The voting system of Music Bank from the South Korean television station KBS

In China, a "milk dump" incident became a moral issue and was criticized by CCTV in early 2021 [10]. This incident has caused a severe social impact and has dealt a blow to the Chinese entertainment industry. Figure 2 shows the QR code on the milk bottle and the cap. Viewers of the talent show Youth with You, can vote for their favorite singers by scanning the QR code on the milk bottle and cap. Many fans bought large quantities of milk just for the QR code on the bottle cap instead of drinking it. At the end, the milk bottle was opened and cannot be resold, so they threw away all the milk and caused severe waste. In the "Kris Wu iTunes Killing Event" in 2018, fans mechanically apply Chinese communication strategies to foreign entertainment cultures, ignoring cultural differences between different countries. Chinese fans' behavior of "data brushing" undermines normal commercial competition among foreign music platforms [11].

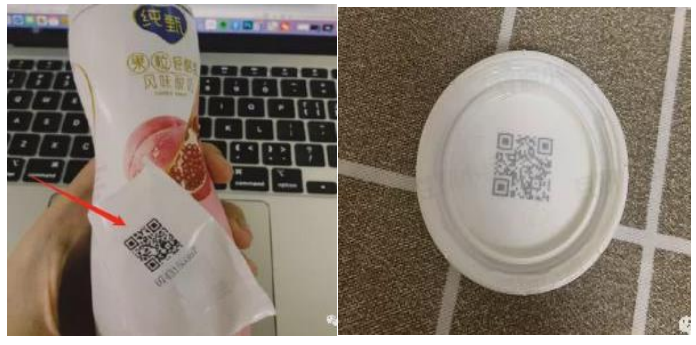

(Note: Pictures from https://www.163.com/dy/article/G9FOLQAN0518BUB4.html)

Figure 2. The QR code on the milk bottle and the cap for people to scan and vote.

South Korea's normative voting system not only levels the playing field for singers but also allows more people to participate in the voting process with four aspects voting ways. Viewers and fans in South Korea can support their favorite group singers through text messages. In contrast, overseas fans and viewers who cannot vote by text messages can support their favorite group singers by buying albums and listening to songs to earn points for the group singers. This voting system allows people from all over the world to participate and is a successful cultural export.

China's unregulated voting system has not only failed to level the playing field for singers. However, it has also led to incidents that violate social morality and have led to internationally negative evaluations of the Chinese entertainment industry. The content of cultural output must be positive. If a country often has events against social morality, it will be difficult for the country's culture to be recognized internationally, and the corresponding cultural output will also become difficult. Therefore, to avoid more similar incidents, it is necessary to formulate a standardized voting system.

\subsection{Business Model Comparison}

This section compares the business model between the group singers from South Korea and the group singers from China. Take WANNA ONE (Table 3.) as an example. WANNA ONE is a limited group chosen by the South Korean talent show Produce 101, and UNINE is a limited group chosen by the Chinese talent show Youth with You. Both groups have a year of group time when they released albums, songs, attended variety shows, and held 
concerts. WANNA ONE was the Top group singer in Korea from 2017 to 2018. That year, they won the Mnet Asian Music Group of the Year award. In 2019, UNINE was also named popular Group Singer of the Year by IQiyi (iqiyi.com). Table 3 shows that WANNA ONE has released 5 albums, 36 songs, attended 12 variety shows. They also held 42 concerts in 7 countries 13 cities. UNINE has released 4 albums, 9 songs, attended 2 variety shows. They held 2 concerts in 1 country's two cities.

Table 3. The number of albums, songs, variety shows, concerts, and concert countries of the group singer WANNA ONE from South Korea and the group singer UNINE from China.

\begin{tabular}{|c|c|c|c|c|c|c|}
\hline Group Name & Album & Song & Variety Show & Concert & $\begin{array}{l}\text { Concert } \\
\text { Country }\end{array}$ & $\begin{array}{c}\text { Concert } \\
\text { City }\end{array}$ \\
\hline WANNA ONE & 5 & 36 & 12 & 42 & 7 & 13 \\
\hline UNINE & 4 & 9 & 2 & 2 & 1 & 2 \\
\hline
\end{tabular}

Comparing the development of WANNA ONE and UNINE, whose debuted from talent shows, the data can be concluded that South Korea and China have significant differences in the business model of group singers. WANNA ONE released only one more album than the UNINE. However, the number of songs, variety shows, concerts, countries, and cities where the concert was held have twice as much the corresponding data of UNINE. The more works a group singer has, the more exposure they will get, and the more people will pay attention to them. So, a group singer with high exposure will be easier to promote cultural exportation than a group with low exposure. Based on the data of "concert", "concert country" and "concert city", WANNA ONE

considered not only South Korean fans but also consider international fans. They hold concerts in other countries to spread the K-pop culture. People or fans who watch the concert are affected by the ambiance. The audience learned about K-pop culture through the concert, and this is a successful manifestation of cultural exportation. UNNIE's music works are far less than WANNA ONE, which causes them to have a low exposure. Many people do not know UNINE, and what music work they have. UNINE did not build a good fan base, and their low exposure is the reason leading to the unsatisfactory cultural exportation.

\subsection{Popularity \& Ranking Comparison}

Table 4. The popularity and ranking of the group singer BTS and TNT on Billboard, YouTube, Bilibili, Twitter, and Weibo.

\begin{tabular}{lcccccc}
\hline Group Name & $\begin{array}{c}\text { Billboard } \\
\text { Weekly Artist } \\
\mathbf{1 0 0}\end{array}$ & $\begin{array}{c}\text { Billboard } \\
\text { Weekly Hot 100 }\end{array}$ & $\begin{array}{c}\text { YouTube } \\
\text { Subscriber }\end{array}$ & $\begin{array}{c}\text { Bilibili } \\
\text { Subscriber }\end{array}$ & $\begin{array}{c}\text { Twitter } \\
\text { Follower }\end{array}$ & $\begin{array}{c}\text { Weibo } \\
\text { Follower }\end{array}$ \\
\hline BTS & 2 & 1 & $53.7 \mathrm{M}$ & - & $37.4 \mathrm{M}$ & $5.6 \mathrm{M}$ \\
TNT & - & - & - & $2.6 \mathrm{M}$ & $8.6 \mathrm{~K}$ & $6.7 \mathrm{M}$
\end{tabular}

"-" means not listed; "M" means million; "K" means thousand. (Billboard Weekly Artist 100 and Billboard Weekly Hot 100 were the international ranking of artists and song which recorded between July 5, 2021, to July 11, 2021. Bilibili is a Chinese famous video platform, like YouTube, people can upload their video on Bilibili.)

BTS is the top group singer in South Korea, and they have a huge fans group around the world. TNT is one of the most popular Chinese group singers in China, they performed on the stage of the CMG 2021 Spring Festival Gala. Artists who can perform on the stage of the CMG 2021 Spring Festival Gala means their strength and social influence are recognized by the public. According to Table 4, BTS has more than 53.7 million fans on YouTube, 37.4 million on Twitter, 5.6 million on Weibo, and no data on the Bilibili platform. BTS won the second place on Billboard Weekly Artist 100 and the first place on Billboard Hot 100. TNT has 2.6 million followers on Bilibili, 8.6 thousand followers on Twitter, 6.7 million followers on Weibo, and no data on YouTube and Billboard.

The success or failure of a group singer and their popularity and social status can be seen from the number of fans, ranking, and the number of followers on the social platforms. The higher the popularity and social status, the more favorable the group singer is for cultural output. Because higher popularity and social status can bring more opportunities for group singers to cooperate with famous artists from other countries for cultural export and dissemination. BTS has more fans and subscribers than TNT on Twitter and YouTube. The international rankings of BTS on Billboard are higher than TNT. BTS has proved their international status by 
winning an award on the Billboard, so they have the chance to cooperate with famous American artists such as Halsey, Nicki Minaj, Lauv, and DJ Steve Aoki to produced songs. When BTS communicates with those singers, they also export the K-pop culture to those singers, and this is also one manifestation of the success of cultural export. However, TNT's international popularity and status are still in a low position, and their official operating account cannot be found on YouTube. TNT is difficult to export culture only by relying on China's popularity and status, they have to achieve a certain popularity and status in the international community to promote cultural exportation.

\section{SUGGESTION}

\subsection{Members with Different Nationalities}

When a company preparing a new group singer, try to consider join one or two members with different nationalities, so that cultural exportation can be carried out easily and effectively, because it is easier for the multicultural group singer to communicate with international fans, and the international development can be formed.

\subsection{Normative Voting System}

Draw lessons from the normative and systematic voting system of South Korean shows to create a level playing field for singers to avoid the occurrence of "milk pouring" incident, which violates social morality, and reduce the impact of such negative news on cultural exportation.

\subsection{Improve Exposure}

Group singers try to create more high-quality music works and participate in variety shows to increase exposure. Try to develop the business as a group-centric business rather than taking the group apart and letting the members do the business separately when the group does not have many exposures. The higher the exposure, the easier it is to drive cultural output.

\subsection{Increase the Popularity and Social Status in the World}

Establish official accounts on overseas social media platforms to manage the media business of group singers in other countries. Releasing performance videos related to group singers to help them increase the attention and popularity of group singers around the world. Do not only focus on one country.

\section{CONCLUSION}

This paper mainly studies the influence of group singers on cultural exportation from member distribution, business model, popularity and ranking, and the norms of the voting system. It also provided data comparison and reasonable suggestions for the Chinese entertainment industry on cultural exportation. The main findings include four aspects. First, a group singer with members of different nationalities can carry out cultural exchange and cultural export more efficiently. Second, a normative voting system can bring a better competitive environment to the entertainment industry. It helps reduce social, morale events, avoid negative effects on cultural output, and criticize some negative lessons to ring the alarm bell for the Chinese entertainment industry. Third, the different business models of group singers lead to different exposure rates, resulting in different cultural output results. The relevant advice is to improve the group singers' exposure rate because the positive influence of the overall exposure rate of a group singer on cultural output is greater than any individual member of the group. Finally, the importance of group singers' success in popularity to cultural export is studied. The higher the popularity, the higher the chance to cooperate with famous artists in other countries, and the easier it is to export culture correspondingly. Based on the findings, this paper gives corresponding suggestions that members with different nationalities, a normative voting system, the exposure of group singers, and the increase of international popularity and social status have a positive influence on cultural output. Cultural exportation is essential for every country, this paper provides some guidance for Chinese entertainment industry to promote cultural exportation and makes contributions to help develop Chinese soft power culture.

\section{REFERENCES}

[1] Y. Hong, Study on the phenomenon that K-pop music promotes "Korean Wave" culture to the world, 2015 , pp.

16-17 https://kns.cnki.net/kcms/detail/detail.aspx?dbcode $=$ CMFD \&dbname $=$ CMFD201601\&filename $=1015$ 431015.nh\&v=ver27LCcQgNrIYRHmOI0z8Iu4V AjFV2xZh3tedqojfoke7L7\%25mmd2FtqpLEs9\%2 $5 \mathrm{mmm} 2 \mathrm{FRrMqNH} 1$

[2] H. Chen, A comparative study on Foreign cultural strategies of China and South Korea, 2020, pp. 7-10. DOI: 10.27316/d.cnki.gswyu.2020.000513

[3] X. L. Meng, The Implication of the Transformation of Korean Popular Culture Into Soft Power on China, 2015, pp. 6-9. https://kns.cnki.net/kcms/detail/detail.aspx?dbcode $=$ CMFD $\&$ dbname $=$ CMFD201502 \&filename $=1015$ 592846.nh\&v=nZ6wsU6XDVvhqY6hwfb26YLU USTDcwUwoktS1Jy10RdA4Wkadm3N38z27xyD DBbW

[4] L. Zhang, Y. N. Hu, From the View of Cultural Export to the View of Cultural Reciprocity: 
Thinking about China's International Communication through the "Korean Wave", 2020, pp. 14-16. https://kns.cnki.net/kcms/detail/detail.aspx?dbcode $=\mathrm{CJFD} \&$ dbname $=$ CJFDLAST2020 $\&$ filename $=\mathrm{ST}$ SD202009007\&v=uRMwk4w0nPjqinnJhQYpWro Qi\%25mmd2B0oFyThI4SgTuqdLJHDnUZ2yBoTf MavoSYizdQb

[5] Y. G. Yu, Y. H. Jiang, Analysis of China's cultural export from the perspective of cultural power, vol. 8, Nan Fang Lun Kan, 2020, pp. 1-3. https://kns.cnki.net/kcms/detail/detail.aspx?dbcode $=\mathrm{CJFD} \&$ dbname $=\mathrm{CJFDLAST} 2020 \&$ filename $=\mathrm{NF}$ LK202008031\&v=ThZdMk8isKs 1314MBH8J9E5 HiwHqv\%25mmd2BluhivDXMB\%25mmd2BMjG 84m0eFKlna0EiQY1gUZUb

[6] N. Li, J. Zheng, A survey of the soft power of Korean pop culture, vol. 8, Yu Wen Xue Kan, 2015, pp. 72-74. DOI: CNKI:SUN:YWXK.0.2015-15032

[7] Z. J. Xu, L. Y. Ma, Y. X. Ma, Study on the dilemma and outlet of China's cultural output, vol. 155, Theoretic Observation, 2019, pp. 153-155. DOI: CNKI:SUN:LLGC.0.2019-05-046

[8] S. Wu, Analysis on the current situation of cultural industry communication between China and South Korea, vol. 22, Chuan Mei Lun Tan, 2019, pp. 159161. DOI: CNKI:SUN:CMLT.0.2019-22-110

[9] Y. J. Wu, L. M. Zang, Exploring the Enlightenment of South Korean culture export mode to China -Taking South Korean film and TELEVISION as an example, Ren Wen Gao Di, 2015, p. 295. DOI: CNKI:SUN:CAIZ.0.2015-14-255

[10] W. Wang, The Cultural Perspective of "Fans Group" and the Ecological Reconstruction of entertainment content -- Reflections on the Event of "Pouring milk", Mei Jie Yan Jiu, 2021, pp. 67-70. DOI: CNKI:SUN:ZGDD.0.2021-07-014

[11] Y. W. Li, The motive force, rule and strategy choice of entertainment culture export, vol. 4, Chuan Mei Qi Kan Xiu, 2019, http://media.people.com.cn/n1/2019/0515/c426841 $-31086127 . h t m l$ 